\title{
"A TORRE AZUL": memórias de espaços escolares pelas narrativas de estudantes e professores (1954-1996)
}

\author{
Lucas Costa Grimaldi \\ Dóris Bittencourt Almeida \\ Universidade Federal do Rio Grande do Sul
}

\section{Resumo}

Oestudo analisa os diferentes espaços ocupados pelo Colégio de Aplicação/UFRGS, a partir de 1954, ano de sua criação, até 1996, quando deixou o Campus Central, transferindo-se para uma sede própria. $\bigcirc$ corpus documental da pesquisa são narrativas de antigos discentes e docentes, publicadas na Revista Cadernos do Aplicação (2004), edição comemorativa aos cinqüenta anos do colégio. Examinamos, nesses escritos, questões referentes à memória, sobretudo a composição das lembranças deste espaço escolar. Cada texto constitui-se em uma versão do passado, pois o rememorar implica em uma construção acerca do que se viveu, atravessada por diferentes clivagens, tendo o presente como fio condutor. Apostamos na potência dessas narrativas como indícios de uma escola de outra época. Por meio delas, aqui transformadas em documentos, são possíveis, pelas lentes da História, aproximações de um tempo pretérito de uma instituição educativa que tem sua história atrelada à Universidade Federal do Rio Grande do Sul. Palavras-chave: Colégio de Aplicação. Universidade Federal do Rio Grande do Sul. Espaço escolar. Cultura escolar.

\section{"THE BLUE TOWER": memories of school spaces by narratives of students and teachers (1954-1996)}

\section{Abstract}

The study analyzes the different spaces occupied by Colégio de Aplicação/UFRGS, from 1954, year of its foundation, until 1996, when it lefts the Central Campus, being transferred to its own place. The research documents are narratives of graduated students and teachers, published in an edition of the Journal of the application (2004), commemorating the 50 years of the college. We examined these writings, memory issues, especially the composition of the memories of this school space. Each text is a version of the past, whose remembrance involves a construction about what lived, crossed by different divisions, having this as a thread. We bet on the power of these narratives as evidence of a school from another time. Through them and the history's lens, here transformed into documents, it is possible to approache a past tense of an educational institution that has its story tied to the Federal University of Rio Grande do Sul.

Keywords: Colégio de Aplicação. Universidade Federal do Rio Grande do Sul. School space. School culture. 


\section{"LA TORRE AZUL": memorias de espacios escolares a través de narra- tivas de estudiantes y profesores (1954-1996)}

\section{Resumen}

El estudio analiza los diferentes espacios ocupados por el Colégio de Aplicação/ UFRGS, desde 1954, año de su creación, hasta 1996, cuando abandonó el Campus Central, transfiriéndose a un núcleo propio. El corpus documental de la investigación son narraciones de antiguos alumnos y profesores, publicados en una edición de la Revista Cadernos do Aplicação (2004), conmemorativa de los cincuenta años del colegio. Hemos examinado en estos escritos, cuestiones referentes a la memoria, especialmente la composición de los recuerdos de este espacio de la escuela. Cada texto se constituye en una versión del pasado, pues el rememorar implica en una construcción acerca de lo que se vivió, atravesada por diferentes clivajes, teniendo el presente como un hilo conductor. Apostamos en la potencia de estas narrativas como evidencias de una escuela de otro tiempo. A través de ellas, aquí transformadas en documentos, son posibles, por las lentes de la historia, aproximaciones a un tiempo pasado de una institución educativa que tiene su historia ligada a la Universidade Federal do Rio Grande do Sul.

Palabras clave: Colégio de Aplicação. Universidade Federal do Rio Grande do Sul. Espacio escolar. Cultura escolar.

Vou contar uma estória

De fatos conhecidos

Agucem as memórias

Preparem os ouvidos

Era uma vez uma torre azul...

(MELLO, 2004)

\section{Introdução}

Essa epigrafe é a primeira estrofe de um poema intitulado "A Torre Azul", escrito por estudantes do Colégio de Aplicação da Universidade Federal do Rio Grande do Sul (CAp/UFRGS), em 1974, último ano em que estavam na escola. Nestes versos, a "torre" representa o lugar ocupado pelo Colégio de Aplicação e, em seguida, pela Faculdade de Educação. Ao longo do poema, os narradores intercalam representações de suas vivências na instituição, permeadas por expectativas, sentimentos, transgressões que marcam o período da transição entre a infância e a idade adulta. 
$\bigcirc$ presente estudo analisa os diferentes espaços ocupados pelo Colégio de Aplicação no Campus Central da Universidade Federal do Rio Grande do Sul, em Porto Alegre, a partir de 1954, ano da criação da instituição de ensino, até 1996, quando deixou esse local, transferindo-se para uma sede própria, no Campus do Vale da Universidade. O corpus documental da pesquisa é constituído por narrativas de memórias de discentes e docentes do Colégio, publicadas, no ano de 2004, em uma edição especial da Revista Cadernos do Aplicação/UFRGS², comemorativa aos cinqüenta anos do colégio. Esta edição conta com quarenta textos de professores, estudantes e diretores em que registram memórias de seus percursos vivenciados na instituição. Destaca-se que o poema apresentado como epígrafe foi reeditado na publicação celebrativa da Revista.

Cabe uma consideração a respeito dos possíveis limites deste corpus documental. Trata-se de um conjunto de textos, reunidos em um periódico de caráter memorialístico, idealizado como parte das ações comemorativas pelo aniversário do Colégio de Aplicação da UFRGS. Entende-se que essas pessoas, por diferentes motivos, foram chamadas a registrar suas memórias de estudante/professor. Acreditamos que houve uma escolha institucional dos 142 escritos que fariam parte da edição. Ainda assim, encontrou-se um texto, produzido por Elisabeth Búrigo (2004, p. 176), que fugiu do tom laudatório, comum às demais narrativas. Ela afirma: "[...] no dia do aniversário, contudo, não pude partilhar das referências idílicas ao passado. Escrevi no mesmo dia uma carta a convite da escola como contribuição para o resgate de uma história que não foi só de acertos".

Entretanto, apesar dessas especificidades, apostamos na potência desses escritos, aqui transformados em documentos, que nos permitem, pelas lentes da História, aproximações de uma instituição educativa, em um tempo pretérito, que tem sua história atrelada à Universidade Federal do Rio Grande do Sul. Cabe destacar o quanto a historiografia vem se interessando por esses relatos de pessoas comuns, que evocam o passado, em uma dimensão autobiográfica. No caso dessa pesquisa, ressaltamos que não se tratam de escritas de foro íntimo e sim produzidas com vistas à publicização, são memórias de sujeitos discentes e docentes que freqüentaram uma instituição de ensino por muitos anos.

O presente trabalho insere-se no campo da História da Educação em suas interfaces com a História da Arquitetura Escolar e a História da Cultura 
Escrita. Examinamos nesses documentos questões referentes à memória, sobretudo o que foi reconstruído como lembranças deste espaço escolar. Assim, cada texto constitui-se em uma versão do passado, tendo em vista que o lembrar é conduzido pelo presente. Produziram-se reflexões acerca do CAp que "[...] reorganizan, redescriben, inventan, omiten y revisan" (PAZOS, 2002, p. 133) o tempo vivido na instituição.

Para compreender o que esses sujeitos dizem sobre a escola que estudaram e/ou trabalharam, buscamos dialogar com Paul Ricoeur (2007) e Agustin Escolano (2017), entre outros autores. Ressaltamos que a institucionalização da escola na Modernidade europeia pressupôs a existência de prédios e espaços próprios para a prática educativa. Por meio do enclausuramento e vigilância, a arquitetura escolar produziu artifícios para o estabelecimento de práticas pedagógicas (VARELA; ALVAREZ-URIA, 1993). Nas últimas décadas, diversos estudos ${ }^{3}$ tiveram como foco a materialidade das escolas, principalmente no sentido de melhor compreender as relações entre as estruturas dessas instituições e os discursos representativos da cultura escolar.

Propomos uma reflexão acerca da dificuldade em desnaturalizar o espaço que habitamos na condição de alunos e/ou professores. Como sujeitos escolarizados, passamos muito tempo imersos nesses ambientes, desdobrados em múltiplos espaços, que podem parecer naturais em meio ao cotidiano vivido. Ricoeur (2007, p. 58) considera que, durante o ato de lembrar, "[...] os lugares habitados são, por excelência, memoráveis". Para ele, "[...] os lugares 'permanecem' como inscrições, monumentos, potencialmente como documentos, enquanto lembranças transmitidas unicamente pela voz voam, como voam as palavras". Escolano (2017, p. 186) complementa, enfatizando o significado do "cenário" escolar nas memórias, pois o espaço da escola produz ressonâncias "[...] na formação dos primeiros padrões do esquema corporal das pessoas e nas primeiras experiências de sociabilidade".

Neste artigo, tematizamos diferentes percepções acerca do Colégio de Aplicação, analisamos memórias desse lugar habitado por muitas pessoas desde a década de 1950. O CAp foi criado no ano de 1954, a partir de esforços da cátedra ${ }^{4}$ de Didática da antiga Faculdade de Filosofia da UFRGS. Até 1966, não possuía um local fixo e enfrentou uma série de disputas com outras unidades da Universidade na busca por um ambiente adequado aonde se instalar. A partir de 1966, passou a ocupar um prédio construído para o Centro de Pesquisas e Orientações Educacionais do RS ${ }^{5}$, e que também abrigou o 
"A TORRE AZUL": memórias de espaços escolares pelas narrativas de estudantes e professores (1954-1996)

Colégio, no Campus Central, onde permaneceu até 1996. Apelidado pelos estudantes de "Torre Azul", possui um estilo modernista, emergente no contexto arquitetônico brasileiro da década de 1960, que destoa da maioria dos edifícios do seu entorno, erguidos no final do século XIX e início do XX. A partir de 1970, a escola passou a compartilhar este espaço com a recém-criada Faculdade de Educação, produto da Reforma Universitáriá.

Antes de partirmos para a análise do conteúdo discursivo das narrativas, consideramos importante descrever como foi organizada essa edição da Revista Cadernos do CAp. Inicia com a apresentação de três textos já publicados em outros números do periódico, um de autoria de Graciema Pacheco, diretora da instituição por quase trinta anos, outro que é um depoimento de Isolda Paes (1994), a primeira vice-diretora, e, ainda, a transcrição do discurso da professora Olga Paraguassu por ocasião de homenagem recebida pela inauguração da Sala de Atividades Múltiplas ${ }^{7}$. Na sequência, um texto de autoria de Vera Regina Moraes, que substituiu Graciema Pacheco na direção, entre 1981 e 1984. E, depois desses quatro registros, a edição especial da Revista exibe redações de professores e estudantes que estiveram no Colégio em décadas pretéritas. Por fim, a homenagem prestada pela Câmara de

144 Vereadores de Porto Alegre aos cinquenta anos da instituição. Ao longo das páginas, também constam fotos alusivas a diversos momentos.

Apresentamos dois mapeamentos dos títulos e autores dos textos que compõem a publicação em questão, um mapeamento refere-se aos textos dos alunos, o outro apresenta os textos dos professores. Também destacamos o período em que estiveram no Colégio, pois, em cada temporalidade, estão implicadas lembranças dos diferentes espaços ocupados pelo CAp no Campus Central da UFRGS. 


\section{Quadro 1}

Títulos e autores dos textos publicados pelos antigos alunos do CAp.

\begin{tabular}{|c|c|c|}
\hline Título & Autor & Período \\
\hline Mágoas de março & Paulo Guedes & 1954-1961 (8) \\
\hline Aplicação-tempo de vida & Rosália Alvim Saraiva & 1957-1963 (7) \\
\hline Meu Aplicação & Cesar Pereira Lima & $1957-1963(7)$ \\
\hline $\begin{array}{l}\text { Velho Aplic, ou ainda " Conceito de Educação } \\
\text { Integral" }\end{array}$ & Carlos Eduardo Legori & 1958-1964 (7) \\
\hline Uma vez aplicação, sempre aplicação! & Philippe Navaux & Turma de 1965 \\
\hline Colégio de Aplicação - 50 anos & Olga Garcia Falceto & $1960-1966(7)$ \\
\hline Discurso de formatura - 1966 & Formandos de 1966 & 1966 \\
\hline $\begin{array}{l}\text { Colégio dos velhos livros e dos velhos } \\
\text { amigos. }\end{array}$ & José Antonio Pinheiro Machado & $1961-1967(7)$ \\
\hline jacaré & Otávio Augusto Licht & Turma de 1967 \\
\hline $\begin{array}{l}\text { "ser diferente" no Aplicação } \\
\text { (1 963-1969):relatos dos encantos e } \\
\text { desencantos na trajetória de uma aluna negra. }\end{array}$ & Maria da Graça Gomes Paiva & 1963-1969 (7) \\
\hline $\begin{array}{l}\text { O roubo da sineta que não houve, ou o colégio } \\
\text { novo que não é mais (rememorações do } \\
\text { Aplicação cinquentenário) }\end{array}$ & Cesar Augusto Guazzelli & 1963-1969 (7) \\
\hline Da redenção ao mundo. & Susana Sondermann Espindola & $1965-1970(6)$ \\
\hline Aplicação, trivial e luxo. & Marco Tulio de Rose & 1965-1971 (7) \\
\hline Colégio de Aplicação e a lista. & Mário Roberto Weyne Correa & 1966-1971 (6) \\
\hline Nossa liga extraordinária. & Produção coletiva de alunos & $\begin{array}{l}\text { Formandos de } \\
1974\end{array}$ \\
\hline $\begin{array}{l}\text { Anos } 70 \text { não deu pra ti, Aplicação, seguimos } \\
\text { aqui! }\end{array}$ & $\begin{array}{l}\text { Nelson Brasil Ferreira } \\
\text { Representando os formandos de } \\
1975 \text { - }\end{array}$ & $1970-1975$ (6) \\
\hline "71-76: born to be wild". & Luciano G. De Mello & $1971-1976(6)$ \\
\hline Aplicação contra o Aplicação. & Elisabete ZardoBúrigo & $1972-1977(6)$ \\
\hline Dos alunos 1974-1980 & Produção coletiva & $\begin{array}{l}\text { Formandos de } \\
1980\end{array}$ \\
\hline $\begin{array}{l}\text { Um caminho para uma concepção } \\
\text { interdisciplinar }\end{array}$ & Adriana Pohlmann & 1976-1981 (6) \\
\hline Um povo difícil de dominar. & Guilherme Cavalheiro Dias Filho & Turma de 1985 \\
\hline Os anos cinza ( Para ler ouvindo "The Wall") & Ney Lemke & 1980-1987 (8) \\
\hline $\begin{array}{l}50 \text { anos de Aplicação } 31 \text { anos com o } \\
\text { Aplicação. }\end{array}$ & Fernanda Luiza Fontoura de Medeiros & 1979-1989 (1 1) \\
\hline Tempos do Aplicação & Eduardo Veiga & Turma de 1989 \\
\hline Retrospecto & Tatiana Golbert & $1981-1991$ (11) \\
\hline
\end{tabular}


"A TORRE AZUL": memórias de espaços escolares pelas narrativas de estudantes e professores (1954-1996)

\begin{tabular}{|l|l|l|}
\hline Era uma vez, no Aplicação.... & Lisiane Alvim Saraiva & 1987-1997 (1 1) \\
\hline $\begin{array}{l}\text { Colégio de Aplicação: comunidade \& } \\
\text { democracia. }\end{array}$ & Nelson de BoerMousalle & 1987-1997 (1 1) \\
\hline
\end{tabular}

Fonte: Elaborado pelos autores.

Em um primeiro olhar para os títulos dos textos e seus autores, é possível tecer algumas análises. Como primeira evidência, o fato de quase todos terem cumprido integralmente sua escolarização no Colégio. Trata-se de uma informação relevante, por considerar as implicações na composição das memórias escolares pela permanência de um longo tempo em uma mesma instituição.

Dos 24 textos individuais, 15 foram escritos por homens e 9 por mulheres. Conforme dito anteriormente, há indícios que houve um convite a determinadas pessoas, por parte da direção e/ou da comissão organizadora dos festejos dos 50 anos do Colégio. Entre os 24 textos, 7 são de autoria de ex-alunos que vieram a ser professores da UFRGS, pode-se pensar que se buscaram essas pessoas pelas proximidades profissionais e pelos laços que unem historicamente o Colégio e a Universidade.

Com relação aos títulos, arriscamos um ensaio de possibilidades, na 146 perspectiva de aproximações temáticas, cientes das questões cifradas que podem estar presentes no que anunciam. Identificamos que, em alguns, se idealiza um determinado modelo de escola, "Uma vez Aplicação, sempre Aplicação!"; "Da Redenção ao mundo"; "Aplicação, trivial e luxo". Outros revelam um tom de nostalgia, intimismo, "Aplicação-tempo de vida"; "O Colégio dos velhos livros e dos velhos amigos"; "O 'ser diferente' no Aplicação (1963-1969): relatos dos encantos e desencantos na trajetória de uma aluna negra"; "O roubo da sineta que não houve, ou o colégio novo que não é mais (rememorações do Aplicação cinquentenário"); "Nossa liga extraordinária"; "50 anos de Aplicação 31 anos com o Aplicação". Há aqueles que fazem referência a elementos culturais e políticos do contexto vigente durante a Ditadura Civil-Militar, "Mágoas de março"; "Anos 70 não deu pra ti, Aplicação, seguimos aqui!"; "71-76: borntobewild"; "Os anos cinza (Para ler ouvindo 'The Wall'1"; "Colégio de Aplicação: comunidade \& democracia". O título "O jacaré" não permite qualquer exercício de especulação acerca de seu conteúdo, mas, ao lermos a redação, percebemos que diz respeito a um elemento da cultura escolar, pois evoca memórias da sineta, um importante artefato da escola, disciplinarizador do tempo. Há enunciados de ordem mais objetiva, 
que não exprimem juízos de valor, nem mesmo sentimentos, "Velho Aplic", ou ainda "Conceito de Educação Integral"; "Colégio de Aplicação - 50 anos"; "O Colégio de Aplicação e a lista"; "Dos alunos 1974-1980"; "Um caminho para uma concepção interdisciplinar"; "Tempos do Aplicação"; "Retrospecto"; "Era uma vez, no Aplicação...". Por fim, dois títulos mais reflexivos que sugerem algum enfrentamento à instituição, afastando-se de um olhar saudosista em relação ao passado, "O Aplicação contra o Aplicação"; "Um povo difícil de dominar".

Neste outro quadro, constam os títulos dos textos produzidos por professores do CAp:

\section{Quadro 2}

Títulos e autores dos textos publicados pelos professores do CAp

\begin{tabular}{|c|c|c|c|}
\hline Título do texto & Autor & Período & Área de ensino \\
\hline $\begin{array}{l}\text { Colégio de Aplicação - } 1981 \text { - } \\
\text { 1984: um inventário de vida }\end{array}$ & Vera Regina Pires Moraes & 1964-1985 & $\begin{array}{l}\text { D i r e to r a } \\
\text { (1981-1984)/ } \\
\text { Didática }\end{array}$ \\
\hline Memórias & Regina Mutti & 1971-1993 & $\begin{array}{l}\text { Diretora (1985-1988) } \\
\text { Língua Portuguesa/ } \\
\text { Literatura }\end{array}$ \\
\hline $\begin{array}{l}50 \text { anos do Colégio de } \\
\text { Aplicação }\end{array}$ & Jorge Luiz Barreto & 1976-2004 & $\begin{array}{l}\text { Diretor (1 989- } \\
\text { 1992/1997-2000/ } \\
\text { 2001-2004)/ } \\
\text { Educação Física }\end{array}$ \\
\hline $\begin{array}{l}\text { Os meus cinquenta anos e os } \\
\text { cinquenta anos do Colégio de } \\
\text { Aplicação }\end{array}$ & Joice Pernigotti & 1974-1998 & Professora \\
\hline $\begin{array}{l}\text { Por orgulho, por respeito e por } \\
\text { muito amor... }\end{array}$ & $\begin{array}{l}\text { PAMPANELLI, Nara } \\
\text { Brasco }\end{array}$ & 1977-1998 & $\begin{array}{l}\text { Lingua Portuguesa e } \\
\text { Literatura }\end{array}$ \\
\hline Mensagem & Luzia Garcia de Mello & 1960-1964 & Professora de História \\
\hline $\begin{array}{l}\text { Alguns fatos pitorescos } \\
\text { ocorridos no período de } \\
1957 / 1971 \text { na área de edu- } \\
\text { cação física. }\end{array}$ & Jaime Lerner dos Reis & 1957-1971 & $\begin{array}{l}\text { Professor de Educação } \\
\text { Física do CAP/UFRGS }\end{array}$ \\
\hline $\begin{array}{l}\text { Quem sou eu para ser um pro- } \\
\text { fessor ideal }\end{array}$ & Sérgio Buttes Cordeiro & $1964-2003$ & Professor de Biologia \\
\hline
\end{tabular}

Fonte: Elaborado pelos autores. 
Entre os convites para escrever, nota-se uma distinção às antigas diretoras. Seguindo a mesma perspectiva de análise anterior, percebemos a recorrência de duas possibilidades temáticas: enunciados que idealizam a escola e outros em que se observa certa neutralidade. Entre os primeiros, "Por orgulho, por respeito e por muito amor..."; "Os meus cinquenta anos e os cinquenta anos do Colégio de Aplicação"; "Colégio de Aplicação - 198 1-1984: um inventário de vida"; "Memórias"; "Quem sou eu para ser um professor ideal". Em número menor, os títulos que indicam uma maior objetividade "Alguns fatos pitorescos ocorridos no período de 1957/1971 na área de educação física"; "Mensagem" e "50 anos do Colégio de Aplicação". Mesmo tendo apenas essa referência, observamos que a maioria dos títulos, tanto os produzidos por antigos estudantes, quanto aqueles escritos por professores, ativos ou aposentados, remetem a uma exaltação do passado vivido na instituição. Assim, podemos perceber o trabalho da composição da memória em cada sujeito, pois o rememorar implica em uma construção acerca do que se viveu, atravessada por diferentes clivagens, tendo o presente como fio condutor. Esses que se puseram a escrever em 2004 eram, na época, pessoas maduras, nem todas mais vinculadas à instituição. Entretanto, produziram várias miradas para 148 a história do Colégio de Aplicação, sendo algumas carregadas de nostalgia. Esse exercício de olhar para os títulos foi a primeira aproximação da potencialidade dessas narrativas. Todavia, aqui o maior interesse está para além, reside em buscar o que eles lembraram sobre o espaço escolar. Neste sentido, o ato de habitar cotidianamente uma instituição escolar, tanto para alunos quanto para professores, é algo que produz enunciados em suas memórias. Optamos por analisar essas discursividades por meio da construção de três categorias: "Espaços do Colégio de Aplicação antes de habitar a Torre Azul"; "Espaços do Colégio de Aplicação como locais de pertencimento" e "Espaços do Colégio de Aplicação e memórias das transgressões estudantis".

Escolhemos estas três categorias, por entender a importância de examinar o espaço proposto pelos arquitetos, e o "[...] experimentado, percebido e vivido como uma experiência subjetiva variável em função de quem convive em um espaço determinado e, inclusive, em diferentes momentos da vida de uma mesma pessoa" (VINAO; BENCOSTTA; 2009, p. 34). Destaca-se a relação entre o que foi construído e as memórias que emergiram a partir da vivência desses espaços. 


\section{Espaços do Colégio de Aplicação antes de habitar a "Torre Azul"}

A história do Colégio de Aplicação da UFRGS, espacialmente, está atrelada ao Campus Central da Universidade. Produto de um tempo, em que muito se discutia acerca de novas concepções pedagógicas, incentivado por duas professoras, o CAp, em seu início, vincula-se ao Departamento de Didática da Faculdade de Filosofia, responsável pelo Curso de Pedagogia e pelas disciplinas pedagógicas dos cursos de licenciaturas.

Nos onze primeiros anos, o Colégio não possuía uma sede fixa ou edifício próprio, esteve, de modo irregular, em diversos lugares no Campus. texto de abertura ${ }^{8}$ da Revista traz palavras de Graciema Pacheco (2004, p. 14) que explica aquela situação do CAp, "[...] de início, a sala de aula foi uma dependência no prédio central da própria Faculdade de Filosofia, com espaços bem definidos e limitados para movimentação, recreação, práticas esportivas e atividades sociais espontâneas". A partir dessas informações, pode-se inferir que esses espaços "definidos e limitados para movimentação" se referem ao fato da escola habitar o ambiente de uma faculdade, que não havia sido projetado para tal fim. Um espaço constituído por outras discursividades, que pertencia a adultos e que teria que ser partilhado com crianças e adolescentes. Destaca-se que naqueles anos 1950, a Universidade era um lugar para poucos e, provavelmente, Graciema Pacheco tenha percebido que havia uma brecha, algum local ocioso, que garantiria à escola deflagrar suas atividades. É possível também, que os conflitos pela divisão do espaço não tenham ocorrido no primeiro ano de fundação da escola, tendo em vista que, em 1954, havia apenas uma turma do primeiro ano ginasial. Entretanto, se percebe que, logo em seguida, esses problemas se acirraram, à medida que o número de alunos aumentou. Paulo Guedes (2004, p. 88), que ingressou na escola em 1955, identifica a "sala 310 da Faculdade de Filosofia" como - lugar dos seus primeiros anos de ensino. Em suas memórias, era um "latifúndio", lugar em que faziam "reuniões dançantes no recreio no fundo da sala". $\bigcirc$ autor informa que, anteriormente, ali se localizava a biblioteca da Faculdade de Filosofia, portanto, talvez fosse um espaço maior que as demais salas de aula. De qualquer modo, é preciso considerar que são memórias de alguém que já viveu muito, evocando seu passado. Nesse sentido, ao rememorarmos os espaços habitados na infância, eles tendem a nos parecer muito maiores, 
"A TORRE AZUL": memórias de espaços escolares pelas narrativas de estudantes e professores (1954-1996)

tendo como referência uma percepção atualizada pelo presente. Isso é próprio do caráter ficcional da memória.

Lendo os 24 textos individuais produzidos pelos estudantes, observa-se que apenas este, produzido por Paulo Guedes, diz respeito ao período em que a escola localizava-se junto à Faculdade de Filosofia. Seis narrativas identificam o período das brizoletas. Portanto, a maior parte dos escritos inscreve-se temporalmente nas memórias do prédio da "Torre Azul".

Esse itinerário de constantes mudanças, evidenciado nessas narrativas, indica que era preciso resistir para manter-se como escola na UFRGS, um lugar de pessoas adultas, em que parecia não haver espaço para crianças e adolescentes. Assim, logo depois de 1954, nota-se que as tensões foram tamanhas no prédio da Faculdade de Filosofia, que o Colégio precisou sair de lá. Sem ter para onde ir, se estabeleceu em uma espécie de galpão, condição precária para a instalação de uma instituição de ensino. Entre as redações, não há nenhuma lembrança deste período, o que indica a provisoriedade dessa ocupação.

Algum tempo depois, em uma tentativa de legitimar-se na UFRGS, e deixar a situação de improviso, foram construídos pavilhões de madeira no estilo brizoletas, em 1960, que abrigaram o CAp até 1966. A construção dessas brizoletas, como política pública de educação no Estado, foi implantada durante o governo de Leonel Brizola (1959-1663), sob o lema 'Nenhuma criança sem escola no Rio Grande do Sul" (QUADROS, 2006). Havia a intenção de disseminar construções escolares pouco onerosas e de rápida montagem, por diversas regiões do território rio-grandense. Segundo Bastos $(2017)^{10}$, a construção dessas edificações no Campus Central da Universidade tinha como objetivo publicizar esse enunciado de expansão escolar,

O Brizola fez uma reunião com todos os prefeitos do Estado do RS, no Salão de Atos da UFRGS, primeiro ele passeou pelo Campus e esse local, que hoje é um estacionamento, estava lá vazio. Quatro horas depois, terminou a reunião e tal, ele voltou e levou todos os prefeitos pra ver que tinha sido construída, nesse intervalo, uma brizoleta. Porque tudo era feito pré-moldado, era pra mostrar, e tinha fotos disso (BASTOS, 2017, p. 2).

Entre as seis narrativas que relatam o tempo das brizoletas no CAp, observam-se duas expressões como uma referência espacial: "barracões de 
madeira", utilizada pela maioria, e "primitivo prédio de madeira" (LIMA, 2004 p. 11 1). Em pormenores, César Lima (2004, p. 111 ) descreve que havia no prédio escolar "[...] quatro salas de aula, dois banheiros, secretaria, sala de professores e da direção onde a austera, mas visionária, Graciema Pacheco imprimia sua competente e particular maneira de dirigir o Colégio [...]". Para além de uma simples descrição espacial, nota-se que, ao mesmo tempo em que rememora a espacialidade, inclui lembranças de uma pessoa, a diretora. Adjetiva a personalidade da mesma, atribuindo a ela características aparentemente incompatíveis, que misturam conservadorismo com inovação, sendo tais percepções presentes em estudos acadêmicos acerca de Graciema Pacheco (ALMEIDA, LIMA, 2015; LIMA, 2016).

ex-aluno se coloca neste ambiente, ao dizer que costumava ir a pé para a escola, "era o primeiro a chegar e gostava de sê-lo". Neste sentido, Pazos (2002), ao analisar autobiografias de estudantes, observa a recorrência da descrição do trajeto de vir para a escola e, nas memórias desses itinerários, evocam-se elementos da paisagem. Portanto, entende-se que o espaço escolar não se resume ao prédio e nem a seu entorno imediato, ele extrapola essas fronteiras, abrangendo as imediações entre a casa e a escola. César Lima (2004, p. 101) também rememora outros usos do espaço escolar, ao sentar "[...] nos bancos longitudinais no puxado que nos resguardava da chuva, ficava estudando e aguardando os demais". Nessa frase, vêem-se outras implicações do autor com o espaço, que evidenciam uma relação sensivel entre o estudante e a escola que habita, intimista, em uma perspectiva de individualidade.

Figura 1

\section{Brizoleta na década de 1960}

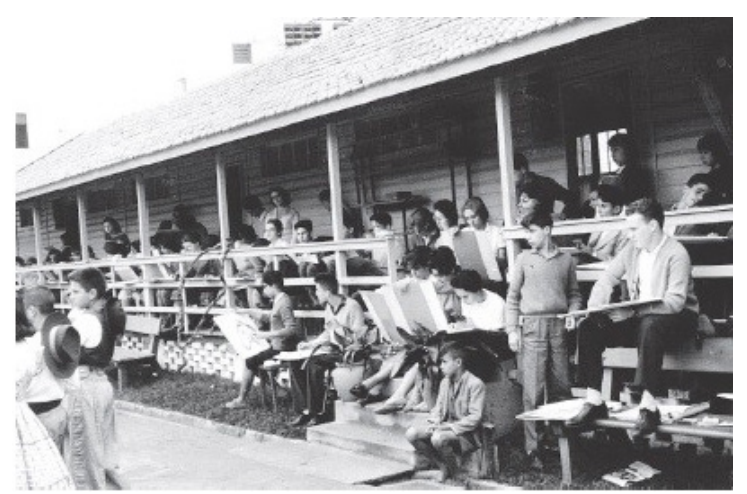

Fonte: Almanaque Gaúcho (2017). 
"A TORRE AZUL": memórias de espaços escolares pelas narrativas de estudantes e professores (1954-1996)

Na Figura 1, temos a fotografia de uma das brizoletas ocupadas pelo CAp. Na imagem, vemos de que forma a constituição espacial possibilita que os estudantes usufruam de sua estrutura, indo ao encontro do que Lima (2004) relatou sobre seus momentos de espera das aulas.

É César Lima (2004) quem explica que, logo depois da edificação da primeira brizoleta, diante da necessidade de mais espaço, construíram-se outrosdois pavilhões e o mais antigo transformou-se em uma espécie de depósito. $\bigcirc$ autor também lembra a construção de duas canchas de vôlei entre os edifícios.

Em outro texto, Cesar Guazzeli rememora o seu ingresso no CAp como "bixo", expressão atribuída aos estudantes calouros da Universidade, apropriada pelos alunos do Colégio de Aplicação. Guazelli percebe a escola como um "monstro" e, nessa associação, estão implicados os sentimentos de um menino vindo do interior do Estado para residir na capital. Passado o susto inicial, logo percebe a

[...] simplicidade material do Aplicação: dois prédios de madeira, no estilo das brizoletas estaduais, com um pátio de terra no centro - asfaltado apenas um ano depois - onde cabiam duas redes para vôlei, um microscópico bar, onde longas filas se formavam para tomar guaraná Caçula, um galpão separado, também de madeira, para as aulas de Artes (GUAZZELLI, 2004, p. 140).

Nessa descrição espacial, inclui memórias da biblioteca, fazendo referência a pessoa responsável por este lugar, "Dona Julieta". Segundo Guazzelli (2004, p. 14 1), "[...] fazia da biblioteca seu santuário, velhota ranzinza ciosa dos livros e dos silêncios [...]".

Ainda sobre esses prédios de madeira, Philipe Navaux (2004, p. $110)$ relata a existência de uma divisão de salas para o recém-criado Curso Colegial, em meados dos anos 1960. O autor lembra minuciosamente a sala que ocupavam, a cada ano, "[...] no terceiro ano, 1965, fomos para as duas salas de aula no último barracão, e a turma se dividiu entre os alunos que iriam para o clássico e os que iriam para as áreas científicas". Sua narrativa indica a expansão da instituição de ensino, inicialmente o Curso Ginasial, na sequência a inclusão do Colegial, com oferecimento do Clássico e Científico. Alguns anos depois, na década de 1970, seria a vez dos anos iniciais de escolarização integrarem a proposta educativa do Colégio de Aplicação. 
Entre todos os relatos que evocam o espaço escolar antes da ocupação da "Torre Azul", encontramos esse que traz uma especificidade por ser uma narrativa da estudante Maria da Graça Paiva (2004, p. 132), que diz ser a "[... única negra do Colégio de Aplicação, naqueles anos". Intitula seu texto "O 'ser diferente' no Aplicação (1963-1969): relatos dos encantos e desencantos na trajetória de uma aluna negra". Entre muitas memórias ressentidas, lembra do apelido "cisne branco em negativo" e, nesse processo que se misturam dissabores, faz uma referência às brizoletas:

[...] mais doloroso ainda era ver meus cadernos novinhos e pastas seguidamente jogados para fora da janela! Sim, para o pátio externo, pois a escola funcionava em dois prédios "brizolinhas", próximo à Faculdade de Arquitetura, fundos da Rádio da Universidade da UFRGS e da Faculdade de Medicina, e não muito longe do famoso bar do Antonio ou bar da Filô, no campus central onde fica a reitoria da universidade (PAIVA, 2004, p. 132).

Naqueles anos 1960, qual seria o percentual de pessoas negras nos ambientes de escolarização, especialmente nos níveis mais avançados? Mesmo sendo uma instituição pública, não se pode esquecer que a seleção para o ingresso discente do CAp era rigorosa com base em diferentes testagens psicológicas e cognitivas (LIMA, 2016). Considerando os indícios que apontam para a pouca presença de alunos negros no CAp, somado às desigualdades raciais constituídas historicamente na sociedade brasileira, é possível pensar que para as crianças e adolescentes negros fosse bastante difícil ser aprovado como aluno do Colégio de Aplicação. Maria da Graça Paiva talvez tenha sido uma das poucas estudantes negras na década de 1960 naquela instituição, o que pode ser encarado por ela como uma espécie de vitória pessoal, entretanto ficamos a imaginar as lutas diárias que precisou enfrentar para ser respeitada naquele lugar. Em uma sociedade instaurada sob o mito da cordialidade racial, suas memórias representam as adversidades na convivência em um espaço que não era de iguais.

Desde 1954, discentes e docentes experimentaram diferentes vivências no Colégio de Aplicação. Inicialmente, ocupou salas do Prédio da Filosofia, depois galpões e brizoletas e, paulatinamente, nesse processo de mudanças, construiu sua legitimidade como instituição educativa de destaque em Porto Alegre. Enfim, transferiu-se para um prédio novo no Campus Central, 
"A TORRE AZUL": memórias de espaços escolares pelas narrativas de estudantes e professores (1954-1996)

que, conforme Luiz Pilla (1960), diretor da Faculdade de Filosofia, foi construído para "[...] alojar o Colégio de Aplicação desta Faculdade e o Centro Regional de Pesquisas Educacionais do Rio Grande do Sul 1", permanecendo neste lugar até o ano de 1996.

\section{Espaços do Colégio de Aplicação como locais de pertencimento}

As memórias da "Torre Azul" ocupam a maior parte dos textos escritos para a Revista, afinal o Colégio esteve por 30 anos nesse prédio, que hoje abriga exclusivamente a Faculdade de Educação da UFRGS.

A documentação consultada indica que, no Campus Central da Universidade, deveria ser projetado um prédio que se adaptasse às necessidades do Centro de Pesquisas Pedagógicas e do Colégio de Aplicação. Em carta ao Instituto Nacional de Estudos Pedagógicos, de 20 de fevereiro de 1960, o então diretor da Faculdade de Filosofia, Luiz Pilla, agradece a quantia enviada pelo Instituto para a construção do prédio que ficou sob a responsabilidade da Divisão de Obras da Universidade. Teve seu projeto assinado pela arquiteta Arlete Schneider ${ }^{12}$. Nesta carta, datada de 1960, Luiz Pilla anunciava alguns

154 detalhes dessa edificação, "[...] o projeto de construção prevê ampla mobilidade das paredes divisórias de modo a adaptar-se ao futuro planejamento das acomodações do Centro, nos quatro últimos pavimentos" (PILLA, 1960) ${ }^{13}$.

Em concepção arquitetônica modernista ${ }^{14}$, a nova edificação estava consonante aos tipos de arquiteturas produzidos no contexto dos anos 1960, no Brasil. Inaugurado no ano de 1965, com nove andares, corresponde ao prédio mais imponente e grandioso do entorno do Campus Central da UFRGS. 
Figura 2

Projeto do prédio do Colégio de Aplicação

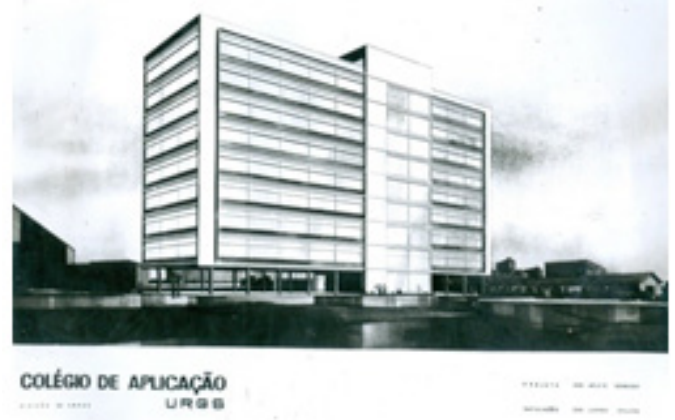

Fonte: Memória FACED.

Figura 3

Construção do edifício

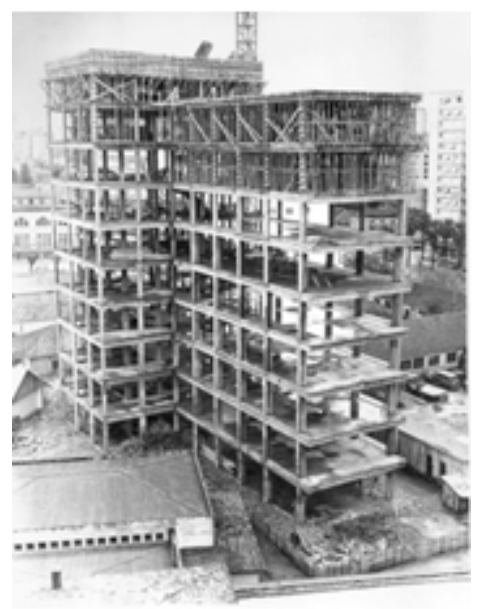

Fonte: Memória FACED.

Daquele contexto, César Guazzeli (2004, p. 87) rememora, "[...] dos velhos barracos de madeira, assistíamos a construção do garboso edifício 
"A TORRE AZUL": memórias de espaços escolares pelas narrativas de estudantes e professores (1954-1996)

de nove andares, apoiado em pilotis, afinado com a melhor arquitetura da época". De 1966, período de inauguração, até 1970, o edifício foi ocupado exclusivamente pelo Colégio de Aplicação. Entretanto, passados esses quatro anos, a Faculdade de Educação, recentemente criada em função da Reforma Universitária, iria dividir o espaço da "Torre Azul" com o Colégio.

Ao longo dos anos, a "Torre Azul" modificou-se internamente e externamente para atender as demandas de seus dois públicos, o Colégio de Aplicação e a Faculdade de Educação. $O$ historiador da arquitetura Leland Roth (2017, p. 10) admite que essas mudanças acabam sendo um problema para a maioria das edificações, pois "[...] poucos edifícios continuaram a acomodar a função para a qual foram originalmente projetados. Isso exigiu ampliações, modificações ou a construção original foi convertida para um novo uso". No edifício do Colégio de Aplicação, esse problema foi reduzido por ter sido construído em uma "planta livre", ou seja, os espaços foram dispostos e organizados através de paredes móveis, ou divisórias facilmente retiráveis, o que configurou uma certa liberdade para as direções de ambas instituições, agirem conforme as demandas.

"O espaço é uma realidade que dura", assim Halbwachs (2004, p.

156 150) entende as interrelações que se estabelecem entre a memória coletiva e os quadros espaciais ocupados em diferentes momentos de nossa existência. Para o autor, esses espaços são possíveis de serem reconstruídos por meio do exercício de imaginação, "[...] é sobre ele que nosso pensamento deve ser fixar, para que reapareça esta ou aquela categoria de lembranças" (HALBWACHS, 2004, p. 150).

Ao examinar o que escreveram os alunos do CAp nessa edição da Revista, emergiu, como algo recorrente, uma representação do colégio como lugar de pertencimento. Pertencer, pertença são palavras que remetem a "fazer parte de" (HOUAISS, 2017), portanto, buscou-se identificar percepções dos autores em relação aos usos do espaço escolar em suas interfaces com o sentimento de acolhida, vinculado a essa instituição. Percebemos que os narradores construíram idealizações sobre o espaço escolar e alinharam as memórias dos prédios ocupados pelo colégio às suas histórias de vida.

É Halbwachs (2004, p. 150 e 167) quem continua auxiliando a compreender a força da presença dos lugares que habitamos em nossas memórias, em sua capacidade de se constituírem em evocadores de lembranças. Ele diz 
"[...] não há, com efeito, grupo, nem gênero de atividade coletiva que não tenha relação com um lugar, isto é, com uma parte do espaço". Na sequência, complexifica a análise, ao explicar que a ideia construída de "[...] um espaço que dura" pode levar o sujeito à formação de uma percepção de "também não mudar" e, assim, imaginar que é possível encontrar "o passado no presente". Em certa medida, essas percepções, eivadas de subjetividades, compareceram nas narrativas selecionadas que se misturam nas lembranças pretéritas em meio a uma construção no presente, afinal o "prédio azul" resiste, embora não seja mais lá o lugar do Colégio de Aplicação na UFRGS.

momento de transição, em que o Colégio deixa as brizoletas que o abrigaram durante 7 anos, é rememorado por vários narradores. Talvez o relato mais impactante seja o de Joyce Pernigotti (2004, p. 57). Assim avalia, "[...] minha sexta série foi desterritorializante". Explica que essa sensação de perda de estabilidade também se deve ao fato de ter feito parte da primeira turma que cursou o ensino polivalente ${ }^{15}$, " $[\ldots$... era a primeira versão do projeto de sexta série numa época em que o ensino ainda era primário, ginásio e colegial" (PERNIGOTTI, 2004, p. 58). De modo distinto, Nara Pampanelli (2004, p. 63) constrói uma narrativa edificante, ao rememorar o mesmo período de transição, "[...] com muito orgulho, ainda me vejo transitando pelas salas do 'velho' e do 'novo' Aplicação".

Voltando para o texto de Joyce Pernigotti (1954, p. 58) a ex-aluna escreve sobre as sensações experimentadas por ser uma das primeiras pessoas a usufruir daquele novo espaço, que contrastava fortemente com os pavilhões de madeira, "tudo muito espaçoso e cheio de novidades". Usa a palavra "chocante" para identificar o salão no segundo andar aonde, ao fundo, foi sua primeira sala de aula. Joyce rememora que nesta ampla sala no segundo andar aconteciam eventos importantes, faz um destaque para a visita do poeta Vinícius de Moraes, "[...] dando um show não só musical, mas também na conversa que a ele se seguiu". Também se lembra da sala de Artes no quinto andar, descreve o lugar como "[...] maravilhoso, nele usávamos materiais completamente novos para mim e fazíamos coisas inimagináveis, como inesquecíveis xilogravuras [...]" Vale ressaltar que a manutenção desse espaço com pias e torneiras, hoje utilizadas pelas estudantes da Pedagogia, talvez seja uma das poucas marcas indicativas de que um dia o Colégio de Aplicação esteve nesse prédio. 
"A TORRE AZUL": memórias de espaços escolares pelas narrativas de estudantes e professores (1954-1996)

José Antônio Pinheiro Machado (2004, p. 123), como Cesar Guazelli, também lembra que observou, das brizoletas, a construção do "[...] garboso edifício de nove andares, apoiado em pilotis, afinado com a melhor arquitetura da época". Para aqueles meninos e meninas dos anos 1960, ter acompanhado o processo de construção de uma obra de tamanha magnitude deve ter sido algo importante a ponto de emergir de suas memórias. José Antonio lembra que o mesmo foi inaugurado em 1966, quando ele iniciava a quarta série ginasial. Da mesma forma que Joyce Pernigotti, rememora as

[...] salas de aulas grandes, vários banheiros, biblioteca, uma marquise que dava para caminhar e pregar sustos em estagiários incautos e, de acordo com as ideias libertarias que ainda vicejavam, uma enorme sala de reuniões capaz de abrigar todos os alunos, professores e funcionários do Aplicação (PERNIGOTTI, 2004, p. 58).

No trabalho das memórias, um prédio, suas salas e marquises assumem dimensões grandiosos pelas palavras de uma mulher madura que rememora o tempo de escola. Nelson Brasil (2004, p. 160) define o Colégio como o "Ateneu às avessas", por meio de evocações sensoriais, lembra-se do cheiro de tinta emanado do "prédio azul", que irradiava pelo "colégio recém-saído das fraldas". Tomado de emoção, explica, "[...] a gente vivencia aqueles ardores, aqueles cheiros todos, aquela ilimitada sensibilidade por tudo, aquela vontade talvez de explodir, tamanha a gana por viver em primeira mão".

Ainda sobre os vínculos construídos no Colégio de Aplicação, vários são os autores que usam de modo recorrente a palavra "liberdade", ao rememorarem a escola que estiveram por muitos anos. Nelson Mousalle, em seu texto, faz aproximações entre o "aprender e o viver", explica que boa parte de sua trajetória escolar aconteceu,

[...] no centro da cidade, junto à Faculdade de Educação. Isso fazia com que eu e meus colegas crescêssemos em um ambiente aberto, sem grades próximas e, devido à distribuição dos horários, prevendo dias de aula em dois turnos, a chance de, em grupo, desbravar as redondezas (MOUSALLE, 2004, p. 212). 
A ideia de liberdade é evocada pelas lembranças de caminhar pelas ruas próximas ao Campus Central da Universidade. Para Nelson, esse sentir-se livre é "fundamental para o desenvolvimento humano e a fixação do caráter". "Um mundo mais repleto de liberdade", um lugar "[...] de menores desigualdades, de maior tolerância, de menos guerras e preconceitos" (MOUSSALLE, 2004, p. 1621, é assim que Nelson Brasil Ferreira percebe o Colégio. E Regina Mutti (2004, p. 38), da mesma forma, valoriza esses sentimentos, em meio aos conflitos pela divisão do prédio com a Faculdade, "[...] o espaço era aberto, no Campus Central, sem muros, gerando cuidados diversos e disputas com a Faculdade de Educação quanto aos limites de uso". Neste sentido, José Hernandez Diaz (2002) explica que a cultura escolar, em toda sua riqueza, também se manifesta fora da escola, em seu entorno. Isso é mais frequente em relação aos edifícios escolares que se localizam em regiões centrais da cidade, em que os estudantes podem circular por outros espaços próximos, ir e vir, especialmente quando há aulas em dois turnos. Para Diaz,

[...] nos referimos a aquellos espacios y lugares de encuentro de los jovenes em La ciudad, que significam El ponto de confluência o de paso para La entrada y salida de escuela, para el recreo, para El encuentro de La pandilla que se forma em La clase o em El colégio [...] para ampliar o combatir La cultura escolar recibida, admitida o impuesta, para crescer em libertad, para juntos y por aprendizage mutuo aprender La vida que se niega em lãs aulas de La escuela (DIAZ, 2002, p. 245).

Em tempos de Ditadura Civil-Militar, nas memórias de Elisabeth Burigo (2004, p. 173) o CAp era como um refúgio, um escape, "[...] um espaço arejado em meio ao sufoco daquele período". Em meio aquele contexto, identifica práticas associadas a outro modelo de escola, "[...] em tempos de 'ame-o ou deixe-o', estávamos dispensados de cantar o hino e hastear a bandeira".

Ao longo de nossa existência, construímos versões da história para nós mesmos, a fim de nos conformarmos e, de certo modo, elaborarmos uma narrativa agradável sobre o passado. Neste sentido, é assim que César Guazzeli (2004, p. 140) compõe, em sua memória, a divisão do prédio entre Colégio de Aplicação e Faculdade de Educação, "[...] tínhamos muito orgulho, e ele nos cegou e fez-nos generosos: como ocupávamos cinco andares, cedemos os pisos superiores para o então Curso de Pedagogia". Tal memória evidencia sua relação de pertencimento à "Torre Azul". 
"A TORRE AZUL": memórias de espaços escolares pelas narrativas de estudantes e professores (1954-1996)

Contudo, Guazzeli (2004, p. 90) ele mesmo percebe que rapidamente "[...] os hóspedes cresceram em relação aos hospedeiros [...]", a distribuição espacial alterou-se em função do número de pessoas a circularem pelo prédio com diferentes finalidades, assim "[...] a sala de reuniões virou biblioteca; fecharam o espaço aberto dos pilotis e fizeram novas salas". Por fim, suas memórias de estudante do CAp se confundem com as memórias de quando era estudante da UFRGS e retornou ao prédio nessa condição, percebe que, naquele momento, "o Aplicação já se constituía num estorvo." Vê-se um tom nostálgico em sua narrativa, considerando o lugar de pertencimento que construiu em suas memórias da escola que estudou por muitos anos.

Assim, Jose Antonio Pinheiro Machado (2004, p. 125 e 147) percebe o envelhecimento da "Torre Azul" e, como num desafio à inexorabilidade do tempo, afirma que o tempo apenas teria passado para o prédio, para ele e seus colegas isso não teria acontecido, "[...] só nós, na velha Aula, não enveIhecemos, continuamos a nos encontrar, a contar as mesmas piadas, que ficam cada vez mais engraçadas. Mas quase tudo mudou do lado de fora daquelas janelas envidraçadas". De outro modo, Susana Espindola percebe a passagem do tempo para o CAp e para ela de modos distintos, se diz "encharcada 160 de tristeza", carrega a convicção de que "[...] esse tempo passou, ficou para sempre nos meandros da saudade".

Uma questão recorrente nessas memórias comovedoras é o ato de sonhar com o tempo passado em algum lugar. Guilherme Dias Filho (2004, p. 186) em seu texto, conta que sonha com o CAp, imagina que está jogando bola, para ele aqueles eram tempos onde "[...] descer as escadas do Aplicação correndo ou deslizando pelo corrimão na hora do recreio para pegar o campinho livre era uma de nossas maiores emoções".

Essas memórias evidenciam sensibilidades de pertencimento a uma instituição educativa, assim, em meio a sentimentos de encontrar no espaço ocupado pela escola liberdade e acolhimento, a percepção de encantamento por habitar um edifício de grandes dimensões, se comparado às brizoletas. 


\section{Espaços do Colégio de Aplicação e as memórias das transgressões estudantis}

Nas narrativas sobre a "Torre Azul", há muitas memórias que remetem a situações que contrariam o conjunto de normas da escola. Em alguns textos, os autores privilegiaram lembrar os momentos em que transgrediam essa normatividade espacial da escola no dia a dia. Hoje podemos tratar como pequenas brincadeiras de crianças em um prédio escolar da década de 1960 e 1970, mas, na época, tratava-se de uma forma, ainda que inconsciente, de transgredir às normativas de uso dos espaços.

Ao considerarmos os edifícios escolares como construções culturais (ESCOLANO, 2001), nas quais emergem diferentes discursividades e relações de poder, não podemos excluir que estas não se dão de modo uniforme. Isto é, cada sujeito que habita este espaço, o faz de forma diferente. Com isso, podemos pensar no que diz Certeau (2008) a partir de seu livro "A invenção do cotidiano", no qual o autor afirma que os sujeitos não são apenas consumidores passivos da cultura, mas que elaboram práticas cotidianas frente a este consumo. Este argumento se assemelha ao de Foucault (2017) quando reflete sobre as relações de poder, sendo este capilarizado, que emerge de diversos pontos e, portanto, não emana, exclusivamente, de uma única autoridade ou do Estado.

"Produtores desconhecidos, poetas de seus negócios, inventores de trithas na selva da racionalidade funcionalista" (CERTEAU, 2008, p. 95). É desse modo que o autor se refere aos sujeitos que de alguma forma elaboram outras experiências a partir do discurso instituído. No caso da "Torre Azul", constavam no Regimento do Colégio de Aplicação (1988) diversas restrições referentes aos estudantes, em relação aos usos do espaço: proibição do uso do elevador pelos estudantes; não havia livre acesso a todos os espaços do prédio; deveriam permanecer em área delimitada no pátio da instituição. Mesmo assim, há muitas narrativas de situações que ignoraram essas normas que, segundo Bastos (2017), eram executadas pelo "olhar vigilante" de dona Iná.

Esses relatos compreendem situações de diferentes ordens, optamos por chamá-las de transgressões frente às normas institucionais. Alguns estudantes, "[...] passavam de uma sala a outra através da marquise, na parte externa do prédio, no quarto ou quinto andares" (FERREIRA, 2004), tendo como 
complemento o relato de Mello (2004, p. 167) "[...] quantas vezes nós, meninos, ou alunos de outras turmas, nos vimos forçados a recolher a pasta escolar das marquises que protegiam as janelas do prédio antigo". Mello ainda caracteriza essa situação como uma "arriscada acrobacia" em que o "retorno era sempre humilhante, pois as janelas da sala eram fechadas pelos colegas, e o caminho terminava passando por outra sala de aulas que estivesse aberta".

Além desses escritos, destacam-se mais exemplos de transgressões pelo mesmo autor: "Que alguns de nós [...] jogavam futebol na própria sala de aula, durante o recreio. As cadeiras de fórmica eram goleiras e a bola, uma proteção de borracha dos pés das mesmas" (FERREIRA, 2004, p. 161). Outro relato refere-se aos alunos que "[...] entupiam com papel a pia da sala de Alemão ${ }^{16}$ e abriam a torneira. Minutos depois, a água escorria por toda a inundada sala" e também "Do estouro da luminária da sala e consequentes nuvens de gás e pedacinhos de papel de cartão de computador, colocados estrategicamente em um saco na parte superior do lustre" (FERREIRA, 2004, p. 162).

Ao observar esses modos de lembrar, podemos pensar, por um lado, que os estudantes não agiam passivamente frente à ordem escolar, e, por outro, que neste processo do lembrar, estão implicadas as ficcionalidades da memória. Mário Correa relembra com saudosismo esse tipo de situação,

[...] quantas vezes passo em frente ao velho prédio [...] ali atrás da Faculdade de Arquitetura e me lembro de quando deixávamos as torneiras da sala de aula de artes, no quinto andar do prédio, abertas e viradas para fora das janelas, formando uma gigantesca catarata e sinto saudade daquele tempo (CORREA, 2004, p. 156).

A narrativa de Mário encontra ressonância no relato da Turma de $1974{ }^{17}$ sobre "[...] no último dia de aula, colocamos fogo nos nossos cadernos, soltamos uma galinha no $2^{\circ}$ andar e ainda ligamos a mangueira dos bombeiros dentro do prédio, (se algum dos nossos filhos fizer hoje tá ferrado)" (TURMA DE 1974, 2004, p. 158). E interessante pensar que nessas memórias privilegiaram-se as transgressões e em momento algum há menção de alguma punição sobre esses atos. Podemos pensar, a partir de Bosi (2015), que isso foi escolhido para rememorar. Houve uma seleção, que é característica da memória, ao privilegiar a lembrança de momentos alegres. Outro aspecto rememorado é trazido por Ferreira, 
Lembrar do Aplicação, na primeira metade dos anos 70, é sentir um afã, é suspirar saudoso pelas lembranças visuais da escada. Ah, bendita, benfazeja, sacra escada. Todo dia, ao bater o sinal no recreio e no final das aulas, nós, guris, despencávamos feito queda d'agua atrás das melhores posições, das mais profundas vistas de nossas femininas colegas. E não havia uniforme, as saias eram curtas, por vezes curtíssimas. Santo Deus. Nunca entrei no proibido elevador. Para quê? [...] (FERREIRA, 2004, p. 160).

Nessas palavras, vêem-se indícios de outras "táticas cotidianas" que relatam, especificamente, de que forma alguns estudantes lidavam com a escada principal do prédio. $\bigcirc$ autor ainda reforça que não precisou entrar no elevador proibido, pois preferia ficar embaixo da escada, observando as colegas que desciam. A partir das normas institucionais, a escada se constituía, para os estudantes, como o único meio de deslocamento entre os cinco primeiros andares e, devido ao padrão arquitetural da edificação, possui um design que possibilita esse tipo de ação dos alunos.

Nelson Ferreira, Luciano Mello, Mário Correa e a Turma de 1974 tratam em seus escritos de memórias narradas no início da década de 1970. Sobre esse período, Elisabete Búrigo (2004, p. 175) considera que o Colégio de Aplicação "[...] era, sim, um espaço arejado em meio ao sufoco daquele período". Este espaço arejado era vivenciado por estudantes que, segundo relato da turma de 1974, "[...] éramos crianças dentro da Universidade". Constata-se que essas pequenas desobediências à ordem escolar, mesmo que minimamente, se constituem em indícios das formas que os sujeitos se utilizam para se apropriar desses espaços que frequentam cotidianamente.

Nas memórias de Nelson Ferreira, Luciano Mello, Mário Correa, estudantes da turma de 1974, privilegiaram-se narrativas de situações que não eram comuns à disciplina da escola. Em um primeiro olhar, podemos considerá-las brincadeiras de crianças, porém, trazem pistas de táticas cotidianas que enfrentam esse "discurso que institui um sistema de valores" (ESCOLANO, 200 1), isto é, o discurso da espacialidade escolar, que produz sujeitos normatizados.

\section{Considerações finais}

Michel de Certeau (2008, p. 202) ao analisar relatos da espacialidade, afirma: "[...] o espaço é um lugar praticado". Este espaço também "[...] 
é o efeito produzido pelas operações que o orientam, o circunstanciam, o temporalizam e o levam a funcionar em uma unidade polivalente de programas conflituais ou de proximidades contratuais".

Neste estudo, analisamos memórias de estudantes e professores, no sentido de buscar compreender os modos como praticavam os espaços do Colégio de Aplicação, tendo como maior foco a "Torre Azul". Tematizaram-se diferentes percepções desse lugar habitado por muitas pessoas desde a década de 1950.

corpus documental consistiu em escritos de antigos estudantes e professores do CAp publicados em uma edição da Revista Cadernos do CAp, celebrativa do seu qüinquagésimo aniversário. Esses sujeitos maduros se dispuseram a fazer o exercício de lembrar e, assim, por meio da composição de suas memórias, mostram percursos dessa instituição de ensino da UFRGS. O estudo alinha-se às perspectivas epistemológicas da História da Cultura Escrita que se interessam pelos "[...] tão variados mundos das escrituras marginais, efêmeras, ordinárias ou personais", concebendo as escrituras como práticas sociais e culturais efetuadas por aqueles e aquelas que se põem a escrever (VIÑAO FRAGO, 2000, p. 10). Neste sentido, podemos considerar os textos, objetos da pesquisa, como "[...] ego-documentos, literatura autorreferencial, ou seja, escrituras em que o sujeito fala ou refere-se a si mesmo, que encontra refúgio e se converte em elemento de referência" (VIÑAO FRAGO, 2000, p. 10).

Aqui, o interesse esteve em buscar o que eles e elas lembraram sobre o espaço escolar, o que produziu enunciados em suas memórias. A partir da análise do conteúdo discursivo presente nas narrativas, percebemos que houve muita idealização ao escrever sobre essa escola que só existe na memória desses estudantes, afinal, "o passado não existe mais" (Informação verbal) ${ }^{18}$. Essas evocações de tempos pretéritos nem sempre são tranqüilas, nem sempre provocam a emergência de memórias felizes. E, mesmo quando há memórias felizes, o narrar parte do presente e, para quem está em idade madura, há uma complexidade em refletir acerca do que passou, nada há de natural nisso.

Assim, César Guazzelli, em seu texto, explica as facetas pantanosas da memória, a mistura entre alegrias, nostalgias e tristezas que comparecem no exercício do rememorar. Para ele, os esquecimentos "[...] talvez tenham mais importância do que as coisas que se manifestam de imediato. Talvez de um conjunto amplo de 'memórias' seja possível uma objetividade mínima 
que reproduza em parte o CAp" (GUAZELLI, 2004, p. 145). $\bigcirc$ ex-aluno complementa, "[...] mas isso é problema para quem eventualmente se dedique à história desse cinquentão. E aqui não escreveu o historiador de ofício, mas um antigo aluno com saudades!". $\bigcirc$ autor tenta separar diferentes lugares de sujeito que ocupou/ocupa: estudante/historiador, mas sabemos que tal tentativa é muito difícil, quiçá impossível, pois essas múltiplas identidades nos definem e nos habitam ao longo da existência e, de diferentes modos, comparecem nos atos de narrar vivências passadas.

Portanto, consideramos essas narrativas como indícios de uma escola de outra época. Estes indícios construíram um Colégio de Aplicação, a partir das lembranças de antigos estudantes e professores. Por meio de seus escritos, permitem que se encontrem frestas para compreender como este espaço escolar foi praticado, vivenciado, efetuando "[...] um trabalho que, incessantemente, transforma lugares em espaços ou espaços em lugares". Esses relatos, em conjunto, pretenderam também "[...] organizar os jogos das relações mutáveis que uns mantêm com os outros" (CERTEAU, 2008, p. 203).

Elaboramos uma história desta escola, a partir da apropriação desses espaços: a sala 310 da Filosofia, as brizoletas e o que foi mais lembrado, a "Torre Azul". Uma "Torre Azul" foi rememorada por sujeitos que a habitaram, sendo possíveis outras tantas. Este espaço escolar foi transformado em lugar de memória (NORA, 1993) pelas narrativas dos antigos estudantes.

\section{Notas}

1 Campus do Vale corresponde a um dos quatro campus da Universidade Federal do Rio Grande do Sul que estão espalhados pela cidade. Situa-se nos limites entre a cidade de Porto Alegre e a cidade de Viamão.

2 Cadernos do CAp é uma revista semestral que publica textos de alunos e professores do Colégio de Aplicação e de outras instituições estudantis, desde o ano de 1986.

3 Podemos citar: Frago e Escolano (1998); Bencostta (2007); Wolff (2005); Ermel (2017); Grimaldi (2016).

4 A professora Graciema Pacheco era titular da disciplina de didática da Faculdade de Filosofia da UFRGS. Diretora do Colégio de Aplicação no período de 1954 a 1981 . Sobre, ver Lima (2016).

5 O centro de Pesquisas e Orientação Educacional do RS pertencente à Faculdade de Filosofia da Urgs era um dos centros regionais do Centro Brasileiro de Pesquisas Educacionais, vinculado ao Instituto Nacional de Estudos Pedagógicos-INEP.

6 Reforma Universitária de 1968, Lei 5.540 (28/11/1968). 
"A TORRE AZUL": memórias de espaços escolares pelas narrativas de estudantes e professores (1954-1996)

7 A sala de atividades múltiplas foi criada no ano de 1993 no térreo do edifício que o Colégio de Aplicação ocupava conjuntamente com a Faculdade de Educação. $\bigcirc$ espaço ocupado pela sala de atividades constituía uma área aberta, cercada de pilotis, que foi fechada por decisão da direção do Colégio de Aplicação.

8 Os textos das professoras Isolda Paes e Graciema Pacheco são republicações de outras edições da Revista Cadernos do Aplicação.

9 Sobre a criação das brizoletas do Colégio de Aplicação, ver Lima (2016).

10 Embora os documentos privilegiados sejam aqueles da Revista Cadernos do Aplicação incluímos essa narrativa de uma entrevista por considerá-la pertinente à discussão das brizoletas. A entrevista pertence ao acervo de Memória Oral do Projeto Memória Faced. Sobre, ver Almeida e Gil (2012).

$11 \bigcirc$ Centro Regional de Pesquisas Educacionais do Rio Grande do Sul foi criado pelo Decreto $n^{\circ}$ 38.460, de 28 de dezembro de 1955. Neste consta que "foram instituídos o Centro Brasileiro de Pesquisas Educacionais e cinco Centros Regionais, o primeiro com sede no Rio de Janeiro, e os demais nas cidades de Recife, Salvador, Belo Horizonte, São Paulo e Porto Alegre" (UFRGS, 1955).

12 Arlete Schneider era arquiteta da Divisão de Obras da Universidade Federal do Rio Grande do Sul.

13 A documentação referente ao convênio UFRGS-INEP se encontra no Arquivo da Faculdade de Educação da UFRGS.

14 A arquitetura moderna, em Porto Alegre, emergiu no final da década de 1940 influenciada pelas escolas de arquitetura do Rio de Janeiro e de São Paulo, que por sua vez foram influenciados pelo movimento vanguardista europeu. Previa um estilo mais funcional, sem rebuscamento, com planta livre e uma arquitetura sob pilotis para trazer leveza. Sobre, ver Luccas (2004).

$15 \bigcirc$ ensino polivalente era o nome dado às classes experimentais. Segundo Lima (2016, p. 103), "[... ] o CAp idealizou algo como uma $6^{a}$ série primária, oferecida aos trinta candidatos suplentes da prova de seleção, de 1963". Estas eram ministradas por professoras polivalentes, que lecionavam as disciplinas de Português, História, Geografia, Biologia e Matemática. Sobre, ver Lima (2016).

16 Os estudantes se referem à sala de língua alemã que se localizava no quinto andar do prédio.

17 A edição comemorativa do Cadernos do Aplicação, além de apresentar 24 textos individuais, também traz textos coletivos de três turmas que se formaram nos anos de 1967, 1965, 1974, 1980 e 1989.

18 Expressão proferida pela professora Maria Teresa Santos Cunha em sua conferência no "Encontro sobre Acervos Escolares: Da costura da memória ao esquecimento" realizado em maio de 2017, na Pontifícia Universidade Católica do Rio Grande do Sul.

\section{Referências}

ALMEIDA, Dóris Bittencourt; LIMA, Valeska Alessandra de. Um Lugar memorável: a Faculdade da Educação/UFRGS, entre afetos e trabalho (1970-2016). Educação e Realidade, Porto Alegre, v. 41 , p. 1347-1370, dez. 2016. (Número Especial). 
- Colégio de Aplicação da UFRGS e suas precursoras: memórias apagadas

(1954-1996). Conjectura: Filosofia e Educação, Caxias do Sul, v. 20, n. 1, p. 14 1-163, jan./abr. 2015.

ALMEIDA, Dóris Bittencourt; Gil, Carmem Zeli Vargas. Um lugar para guardar memórias de uma Faculdade de Educação: o projeto "Memória FACED" (1970-20 1 1). In: CONGRESSO LUSO-BRASILEIRO DE HISTÓRIA DA EDUCAÇÃO, 9; 2012, Lisboa. Anais... Lisboa: Universidade de Lisboa, 2012.

BASTOS, Maria Helena Camara. Entrevista. Porto Alegre, 10 maio. 2017.

BENCOSTTA, Marcus Levy (Org.). História da educação, arquitetura e espaço escolar. São Paulo: Cortez, 2005.

BOSI, Ecléa. Memória e sociedade: lembranças de velhos. 6. ed. São Paulo: Companhia das Letras, 2015.

BURIGO, Elisabete Zardo. O aplicação contra o Aplicação. Cadernos do Aplicação, Porto Alegre, v. 17, n. 1/2, p. 173-176, jan./dez. 2004.

CERTEAU, Michel de. A invenção do cotidiano. 15. ed. Tradução Ephraim Ferreira Alves. Petrópolis: Vozes, 2008.

CORRÊA, Mário Roberto Weyne. O Colégio de Aplicação e a lista. Cadernos do Aplicação, Porto Alegre, v. 17, n. 1/2, p. 153-156, jan./dez. 2004.

DIAS FILHO, Guilherme Cavalheiro. Um povo difícil de dominar. Cadernos do Aplicação, Porto Alegre, v. 17, n. 1/2, p. 185-188, jan./dez. 2004.

DIAZ, José Hernandez. Etnografia e Historia material de La escuela. In: ESCOLANO BENITO, Agustin; HERNANDEZ DIAZ, Jose Maria (orgs.). La Memoria y el Deseo: cultura de La escuela y educacion deseada. Valencia: Tirant lo Blanch, 2002.

ERMEL, Tatiane de Freitas. O "gigante do alto da bronze": um estudo sobre o espaço e arquitetura escolar do Colégio Elementar Fernando Gomes em Porło Alegre/RS 11913 1930). 2011 1. 173 f. Dissertação (Mestrado em Educação) - Programa de Pós-Graduação em Educação/PPGE, Pontifícia Universidade Católica do Rio Grande do Sul, Porto Alegre, 2011 .

ESCOLANO, Agustin. Arquitetura como programa. Espaço-escolar e currículo. In: VIÑAO FRAGO, Antonio; ESCOLANO, Agustín. Currículo, espaço e subjetividade: a arquitetura como programa. Tradução Alfredo Veiga-Neto. Rio de Janeiro: DP\&A, 2001.

A escola como cultura: experiência, memória e arqueologia. Tradução Vera Lúcia

Gaspar da Silva. Campinas: Alinea, 2017. 
"A TORRE AZUL": memórias de espaços escolares pelas narrativas de estudantes e professores (1954-1996)

ESPÍNDOLA, Susana Sondermann. Da redenção ao mundo. Cadernos do Aplicação, Porto Alegre, v. 17, n. 1/2, p. 147-148, jan./dez. 2004.

FERREIRA, Nelson Brasil. Anos 70 não deu pra ti, Aplicação, seguimos aqui! Cadernos do Aplicação, Porto Alegre, v. 17, n. 1/2, p. 159-164, jan./dez. 2004.

FOUCAULT, Michel. Microfísica do poder. 6. ed. Tradução Roberto Machado. Rio de Janeiro: Paz e Terra, 2017.

GUAZZELLI, Cesar Augusto. O roubo da sineta que não houve, ou o colégio novo que não é mais (rememorações do Aplicação cinquentenário). Cadernos do Aplicação, Porto Alegre, v. 17, n. 1/2, p. 139-146, jan./dez. 2004.

GUEDES, Paulo Coimbra. Mágoas de março.Cadernos do Aplicação, Porto Alegre, v. 17, n. 1/2, p. 85-96, jan./dez. 2004.

HALBWACHS, Maurice. A memória coletiva. 2. ed. Tradução Beatriz Sidou. São Paulo: Centauro, 2004.

HOUAISS, Antonio. Dicionário da Língua Portuguesa. Disponível em: https://houaiss.uol. com.br. Acesso em 10. dez. 2017.

LIMA, Cesar Pereira. Meu aplicação. Cadernos do Aplicação, Porto Alegre, v. 17, n. 1/2, p. 101-104, jan./dez. 2004.

LIMA, Valeska Alessandra de. O Colégio de Aplicação da UFRGS: práticas educativas adormecidas entre o arquivo e a memória oral (1954-1981). 2016. 150f. Dissertação (Mestrado em Educação) - Programa de Pós-Graduação em Educação, Universidade Federal do Rio Grande do Sul, 2016.

MACHADO, José Antonio Pinheiro. $\bigcirc$ Colégio dos velhos livros e dos velhos amigos. Cadernos do Aplicação, Porto Alegre, v. 17, n. 1/2, p. 123-126, jan./dez. 2004.

MELLO, Luciano Gonçalves de. "71-76: born to be wild". Cadernos do Aplicação, Porto Alegre, v. 17, n. 1/2, p. 165-172, jan./dez. 2004.

MOUSSALLE, Nelson de Boer. Colégio de Aplicação: comunidade \& democracia. Cadernos do Aplicação, Porto Alegre, v. 17, n. 1/2, p. 207-216, jan./dez. 2004.

MUTTI, Regina Maria Varini. Memórias. Cadernos do Aplicação, Porto Alegre, v. 17, n. 1/2, p. 37-52, jan./dez. 2004.

NORA, Pierre. Entre Memória e História: a problemática dos lugares. Projeto História, São Paulo, v. 10, n. 1, jul./dez. 1993. 
PACHECO, Graciema. Colégio de Aplicação: A busca da espontaneidade, da comunicação e da interação social criadora. Cadernos do Aplicação, Porto Alegre, v. 17, n. 1/2, p. 10-16, jan./dez. 2004.

PAES, Isolda Holmer. Depoimento da professora Isolda Paes: mensagem a professores e alunos. Cadernos do Aplicação, Porto Alegre, v. 7, n. 1, p. 17-20, jan./jun. 1994.

PAIVA, Maria da Graça Gomes. $O$ "ser diferente" no Aplicação (1963-1969): relatos dos encantos e desencantos na trajetória de uma aluna negra. Cadernos do Aplicação, Porto Alegre, v. 17, n. 1/2, p. 131-138, jan./dez. 2004.

PAMPANELLI, Nara Brasco. Por orgulho, por respeito e por muito amor... Cadernos do Aplicação, Porto Alegre, v. 17, n. 1/2, p. 63-66, jan./dez. 2004.

PAZOS, Mercedes Suarez. Historias de Vida y Fuente Oral. Los recuerdos escolares. In: ESCOLANO BENITO, Agustin; HERNANDEZ DIAZ, Jose Maria (Org.). La memoria y el deseo: cultura de La escuela y educacion deseada. Valencia: Tirant lo Blanch, 2002.

PERNIGOTTI, Joyce Munarski. Os meus cinquenta anos e os cinquenta anos do Colégio de Aplicação. Cadernos do Aplicação, Porto Alegre, v. 17, n. 1/2, p. 57-62, jan./dez. 2004.

PILLA, Luis. [Carta] 20 fev. 1960, Porto Alegre [para] TEIXEIRA, Anísio. Rio de Janeiro. If. Encaminha projeto do imóvel a ser construído em regime de cooperação.

QUADROS, Claudemir de. Reforma, ciência e profissionalização da educação: O Centro de Pesquisas e Orientação Educacionais do Rio Grande do Sul. Porto Alegre: UFRGS, 2006. 429f. Tese (Doutorado em Educação). Programa de Pós-Graduação em Educação, Universidade Federal do Rio Grande do Sul, Porto Alegre, 2006.

RICOEUR, Paul. A memória, a história, o esquecimento. 6. ed. Tradução Alain François. Campinas: Unicamp, 2007.

$\mathrm{ROTH}$, Leland. Entender a arquitetura. Seus elementos, história e significado. Tradução Joana Canedo. São Paulo: Gustavo Gili, 2017.

TURMA de 1974. Nossa liga extraordinária. Cadernos do Aplicação. Porto Alegre, v. 17, n. 1/2, p. 157-158, jan./dez. 2004.

VARELA, Julia. ALVAREZ-URIA, Fernando. A maquinaria escolar. Teoria \& Educação, São Paulo, v. 1, n. 6, p.225-246, dez. 1993.

VIÑAO FRAGO, Antonio; ESCOLANO BENITO, Agustín. Currículo, espaço e subjetividade: a arquitetura como programa. Tradução Alfredo Veiga-Neto. Rio de Janeiro: DP\&A, 2001 . 
"A TORRE AZUL": memórias de espaços escolares pelas narrativas de estudantes e professores (1954-1996)

VINAO FRAGO, Antonio; BENCOSTTA, Marcus Levy. Entre a multidisciplinariedade e a história: o espaço e a arquitetura escolares nas recentes historiografias educativas espanholas e brasileira. In: ARAUJO, Marta Maria de. (Org.). História(s) Comparada(s) da Educação. Brasília: Liber Livro, 2009.

VINAO FRAGO, Antonio. A modo de prologo, refugios del yo, refugio de outros. In: MIGNOT, Ana; BASTOS, Maria Helena Camara; CUNHA, Maria Teresa Santos (Org.). Refúgios do eu: educação, história e escrita autobiográfica. Florianópolis, 2000.

Doutorando Lucas Costa Grimaldi Universidade Federal do Rio Grande do Sul | Porto Alegre Programa de Pós-Graduação em Educação Grupo de Pesquisa Educação no Brasil: Memórias, Instituições e Cultura Escolar | EBRAMIC | CNPQ

E-mail | lucascgrimaldi@gmail.com

Profa. Dra. Doris Bittencourt Almeida Universidade Federal do Rio Grande do Sul | Porto Alegre Faculdade de Educação Programa de Pós-Graduação em Educação Grupo de Pesquisa Educação no Brasil: Memórias, Instituições e Cultura Escolar | EBRAMIC | CNPQ E-mail | almeida.doris@gmail.com

Recebido 10 abr. 2018 Aceito 3 maio 2018 